\title{
The Use Of Internet By Educational Institutions: The Case Of Greece
}

Panopoulos Anastasios, (Email: tasos@aueb.gr), Athens University of Economics and Business, Greece Ventoura Neokosmidi Zoe, (Email: ventura@aueb.gr), Athens University of Economics and Business, Greece

\begin{abstract}
The purpose of this study is, to investigate the use of the Internet by Greek educational institutions (universities and polytechnics) in the field of public relations. A study of one hundred web sites, randomly selected from a list of four hundred sixteen web addresses found in the web site of Gunet (www.gunet.gr), reveals how new technologies help universities to build relationships with publics. All the selected web sites were examined in terms of: (1) ease of interface, (2) usefulness of information, (3) generation of return visits, (4) conservation of visitors and (5) dialogic loop. Content analysis was used for the gathering of the data.
\end{abstract}

\section{INTRODUCTION}

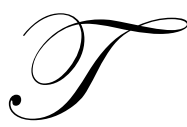

1997, Esrock \& Leichty 1998, 1999, Kent \& Taylor 1998).

he capability of the Internet as a public relation tool has attracted intense academic interest and commercial development. Most of the studies investigated the ways organizations or corporations utilize their web sites for public relations communication purposes (Chang, Arnett, Capella \& Beatty,

Universities were pioneers in the effort of creating and evolving the Internet to what is known today as World Wide Web. Daugherty and Funke (1998) report that universities use video conferencing, web base course instruction, and a number of Internet applications. According to them the innovation of the Internet has a profound impact on universities practices and policies changing the traditional definition of education (Daugherty \& Funke 1998).

This study will examine the use of the web sites of Greek educational institutions for the creation and maintenance of relations with their publics. Web sites in general fulfill two basic goals or functions: a) to provide information b) to manage relationships with publics. Content analysis will reveal the extend to which web sites are used by educational institutions in order to accomplish the basic functions mentioned above.

This paper is organized as follow: in Section II the Theoretical background is described, in Section III a depth analysis of the Research Method is organized, in Section IV the Results of the study are presented and finally in Section $\mathrm{V}$ the conclusion follows.

\section{THEORETICAL BACKGROUND}

The use of the Internet as a communication medium is very popular due to the advantages that it appears compared to other communication mediums. The Internet has a 24 - hour world wide broadcasting capability, enabling information dissemination, and collaboration and interaction between individuals and their computers regardless of the geographic location (December and Randal 1996, Vibert 2000). The elimination of time and space in combination with the low cost makes the Internet a suitable medium for the practice of public relations. 
Internet can be classified as a mass communication medium, as well as, a one to one communication medium. As a public relation tool it can be used in order to disseminate symbolic content to large heterogeneous and geographically isolated audiences - mass communication - but it can also be used to build one to one relationships at the same time - one to one communication - . Web sites produce mass messages targeted at different stakeholders (Heath 1998) while the use of interactive communication technologies create a virtual group of distanced individuals who dialogue with the use of computers (Rogers \& Allbritton 1995).

Heeter (1989) defined interactivity, as a multi-dimensional concept that includes: complexity of choice, available effort users must exert, responsiveness to the user, monitoring information use, ease of adding information and facilitation of interpersonal communication. The usefulness of the Internet is changing daily with faster speeds more information and web sites, and new functions. With interactive technologies rapidly transforming the marketplace and our society, (Kannan, Chang \& Whinston 1998, Roland \& Varik 1996) the once passive users are empowered to become active and interactive. Interactivity is capable of enabling real time two-way communication and dialogic communication between users.

Dialogue has been considered as the most ethical form of public relations as well as one of the key features of the symmetrical model (Taylor et al. 2001). The Internet offers the possibility of dialogue and interactivity, which other media cannot easily replicate (Peterson et al 1997). Organizations must aim to design their web pages to facilitate relationships with the organization's publics through real dialogue (Kent \& Taylor 1998). However according to the findings of relevant researches (Kent 2001, Taylor et al 2001, Kent \& Taylor 1998, 2002, Kent et al. 2003, Naude et al. 2004), there is a gap between the implementation of the dialogic principles and the actual dialogic capabilities that the web sites offer.

In order to examine dialogic relationship building through the Internet this study examines the extend to which Greek educational institutions incorporate the five dialogic principles as described by Kent \& Taylor (1998) through the answering of the following research questions:

RQ1: What are the dialogic characteristics of educational institutions web sites? Web sites of educational institutions will be examined, through the use of content analysis, if they include and to what extend variables that outline the five dialogic principles.

RQ2: What are the differences (if any) between the internal and external publics that are targeted by educational institutions websites? Past researches, (Kent \& Taylor 2002, Esrock \& Leichty 1999) based on the fact that the purpose of a web site is to serve different stakeholder groups, investigated if web sites were more oriented to the service of a specific public. Results revealed that although organizations tried through their web sites to serve their publics there were differences to the extend that each public was served. In this study we separated publics to internal, including those that connect in some way with the educational institutions (for example students, scholars, e.t.c), and external including those that do not connect in any way with the educational institutions. The following hypothesis was formulated based on the results of previous studies:

H1: Educational institutions websites will be more useful to internal publics than to the external publics.

RQ3: How effectively do educational institution's web sites employ dialogic principles? This question attempts to link the design and the content of the web sites of educational institutions with the adoption of dialogic behavior. The connection between the dialogic principles that a web site incorporates and its actual dialogic behavior is examined. Since a request for information is an opportunity for an educational institution to engage in dialogic communication the following hypothesis was formulated:

H2: Educational Institutions that respond to requests for information will be more dialogic than those that do not respond to such requests. 


\section{RESEARCH METHOD}

The coding procedure took place between the first of March and the 30 of April. This study used the Gunet site (www.gunet.gr) creating a random systematic sampling of $100(24 \%)$ of the list's web addresses - four hundred sixteen in total - selecting every third case after a random start. The Gunet stands for Greek Universities Network Portal and as a result this web site is the official site of the Greek educational institutes overall.

During the period of time that the research took place three coders - all of them postgraduate students of the Athens University of Economics and Business - were used to code thirty variables for each web site. Every variable was coded with zero if the variable did not exist or with one if the variable did exist. These thirty variables derived from the five principles of dialogic relationship (Kent \& Taylor 1998).

\section{The Five Principles Of Dialogic Relationship (Kent \& Taylor 1998)}

\section{Ease Of Interface}

The dialogic principle of ease of interface is based on the idea that visitors should have an easy time navigating a site and finding information (Taylor et al. 2001). Since easy navigation is identified as key element of ease of interface then the existence of a site map function should be a variable with which we can measure the ease of interface. The existence of a site map in a web site could be very helpful for the user since he could see the entire content of the site in one screen and he could be guided with just one mouse click. A second variable that could contribute to the use of interface is the existence of a search engine in a web site. The role of a search engine is to help the user locate the information that he wants with the use of a single word or phrase. Additional help could be given to the visitor of a site through the use of links. The creation of links with the other departments of the same university is considered a valuable help to the visitor. Finally web sites should not be designed to be accessible only by users who have the latest software or hardware. Efficiency and download speed should be taken into account because too many graphics at the beginning of a site might annoy users. That is why a variable called low graphic reliance was created. Ease of interface is a predictor of dialogic potential because if a site is not "user friendly" then visitors will not have a positive experience at the site and may not be encouraged to return (Taylor et al. 2001).

\section{Usefulness Of Information}

Since the visitor of a web site could be anyone, sites should make an effort to include information of general value to all publics. A web site serving a public relation function should not only be a well organized information extension of an educational institution but also should create positive attitudes by being easily accessible to all publics and by providing all publics - both generic and particular - with useful information (Kent \& Taylor 1998). According to Esrock and Leichty $(1999,2000)$ certain publics are more targeted than others. In our case we created two different categories of public, the internal public which is consisted by visitors who have a direct relationship with the academic institution - for example students, teachers - and the external public which is consisted by visitors with an indirect relationship with the academic institution - for example parents, people who are interested about the specific university but they are not members of it - .

Variables that measure the usefulness of information for the internal public are: mission statement philosophy, access to the library electronically, the timetable of the semester, information describing the steps that you need to follow in order to enroll to the university or the semester, student's care. On the other hand for the external public the variables that we use are: information about postgraduate studies, information about graduate studies, location and access to the university, telephone numbers, announcements, proclamations. Assuming that visitors that consist these two different publics have different needs, the variables of the external and internal publics describing the usefulness of information are different, in an effort to describe and elevate those differences. 


\section{Generation Of Return Visits}

Relationships are not established in one-contact communication interactions so the principle of return visits establishes the conditions upon which relationship building can take place (Taylor et al. 2001). Simply updating information or trying to include information that the organization believes to be interesting would be reverting to a one - way communication. Relationship building requires time trust and a variety of other relational maintenance strategies that can only occur over repeated interactions (Taylor et al. 2001)

Features of the web site that encourage visitors to return include: appealing to visitors with explicit statement inviting them to return, encourage visitors to bookmark the main page at their Favorites, the existence of Forums or Chat rooms, the existence of FAQs (Frequently Asked Questions) or Q\&A (Question and Answers), a calendar of events for the academic year, regular updates with new information - one update at least every month - , easily downloadable files, the e-mail of a contact person (for example the developer of the web site) for questions, some useful links to other web sites.

\section{Conservation Of Visitors}

Time is a critical factor for the creation and the development of a relation. Visitors of a web site usually spend little time trying to find information that adds value to them. Time pressure can easily damage the relation that we want to create between the web site and its publics so it is essential to ensure that visitors will spend as much time as possible exploring the web site. In this study three variables were used for the measurement of conservation of visitors: the presence of important information in the main page since it is possible to attract a visitor and nail him for some time, the post of the date that the site was last updated because the user is informed when new information are posted and is not annoyed reading old data that he could have read in his previous visits, the amount of time that the web site needs in order to load - less or more than four seconds - using the local network of the Athens University of Economics and Business and a personal computer.

\section{Dialogic Loop}

Even if a web site follows the suggestions of the first four dialogic principles it cannot be fully dialogic if it does not offer and follow through on two-way communication (Taylor et al. 2001). This can be obtained only with the use of interactivity and feedback procedures.

Universities cannot engage in electronic communication and then not respond to messages from publics. Many educational institutions wrongly believe that their presence on the Internet is more important than the service of their publics. The variables that best describe the principle of dialogic loop are: opportunities for the users to make on line applications, e-mail address of the network operation center of the university and response to a question with the use of e-mail, e-mail address of the secretary's office of the university and response to a question. Each one of the three variables that were used can create a dialogic loop.

\section{RESULTS}

To calculate the reliability coefficient, this study used Scott's pi (Meyer 2002). This coefficient was calculated from the data of the three coders with the results of reliability 0.85 between Coder A and Coder B, 0.81 between Coder A and Coder C, and 0.82 between Coder Ban Coder C. Considering the reliability between the three coders the overall coefficient was 0.83 . According to Meyer (2002) there is no firm rule for a minimum Scott's pi, but most of the literature in mass communication research cites values of 0.75 or higher.

The principle of ease of interface was analyzed in 100 web sites with the use of four variables. Scores were computed by dividing the number of observed " 1 " responses on the items comprising the index by the number of total items in the index and treating the result as a percentage. From the Table 1.1 it is obvious that the majority of the web sites contain three variables (32\%) followed by web sites containing two variables (24\%). Only seven web sites (7\%) do not provide any of the selected variables. 
Table 1.1

\begin{tabular}{|l|c|c|c|c|c|}
\hline & & Frequency & Percent & Valid Percent & $\begin{array}{c}\text { Cumulative } \\
\text { Percent }\end{array}$ \\
\hline Valid & 0 & 7 & 7.0 & 7.0 & 7.0 \\
\hline & 1 & 17 & 17.0 & 17.0 & 24.0 \\
\hline & 2 & 24 & 24.0 & 24.0 & 48.0 \\
\hline & 3 & 32 & 32.0 & 32.0 & 80.0 \\
\hline Total & 4 & 20 & 20.0 & 20.0 & 100.0 \\
\hline
\end{tabular}

In order to answer RQ2, the principle of usefulness of information was investigated after the distinction between internal and external publics. Six variables were used for the description of the relationship with the external public. The majority of the web sites $(30 \%)$, as it is shown form the Table 1.2, contained the six variables that were used followed by those containing five variables (23\%). The less the variables that appear in a web site, the less is the percentage of the web sites that contains them. The above leads to the conclusion that the orientation of the web sites of educational institutions is to inform and serve the needs of their external public.

Table 1.2

\begin{tabular}{|l|c|c|c|c|c|}
\hline & & Frequency & Percent & Valid Percent & Cumulative Percent \\
\hline Valid & 0 & 1 & 1.0 & 1.0 & 1.0 \\
\hline & 1 & 4 & 4.0 & 4.0 & 5.0 \\
\hline & 2 & 12 & 12.0 & 12.0 & 17.0 \\
\hline & 3 & 13 & 13.0 & 13.0 & 30.0 \\
\hline & 4 & 17 & 17.0 & 17.0 & 47.0 \\
\hline & 5 & 23 & 23.0 & 23.0 & 70.0 \\
\hline Total & 6 & 30 & 30.0 & 30.0 & 100.0 \\
\hline
\end{tabular}

The study of the variables used for the internal public - five variables - is depicted below (Table 1.3). At least one variable is contained in every web site examined with the majority of the web sites containing all the variables. It is obvious that the vast majority of the web sites of educational institutions provide information and support to their internal public.

The hypothesis $\mathrm{H} 1$ is not supported from the data. It is true that educational institutions are more useful to their internal publics $(72,8 \%)$ than their external publics $(71,67 \%)$ but the difference is negligible.

Table 1.3

\begin{tabular}{|l|c|c|c|c|c|}
\hline & & Frequency & Percent & Valid Percent & $\begin{array}{c}\text { Cumulative } \\
\text { Percent }\end{array}$ \\
\hline Valid & 1 & 5 & 5.0 & 5.0 & 5.0 \\
\hline & 2 & 16 & 16.0 & 16.0 & 21.0 \\
\hline & 3 & 23 & 23.0 & 23.0 & 44.0 \\
\hline & 4 & 22 & 22.0 & 22.0 & 66.0 \\
\hline Total & 5 & 34 & 34.0 & 34.0 & 100.0 \\
\hline
\end{tabular}

Educational institutions contain at their web sites elements supporting the conservation of visitors as it is shown from the table 1.4 below. 
Table 1.4

\begin{tabular}{|l|c|c|c|c|c|}
\hline & & Frequency & Percent & Valid Percent & $\begin{array}{c}\text { Cumulative } \\
\text { Percent }\end{array}$ \\
\hline Valid & 0 & 3 & 3.0 & 3.0 & 3.0 \\
\hline & 1 & 31 & 31.0 & 31.0 & 34.0 \\
\hline & 2 & 39 & 39.0 & 39.0 & 73.0 \\
\hline & 3 & 27 & 27.0 & 27.0 & 100.0 \\
\hline Total & 100 & 100.0 & 100.0 & \\
\hline
\end{tabular}

For the measurement of generation of return visits nine variables were used. The majority of the web sites contain five variables $(25 \%)$ followed by those containing four $(20 \%)$. It is remarkable the fact that no web site was found containing all the nine variables or at least the eight of them. Seven variables $(8 \%)$ were the maximum number that a web site appeared and there were web sites (5\%) that did not contain any variable at all.

Table 1.5

\begin{tabular}{|l|c|c|c|c|c|}
\hline & & Frequency & Percent & Valid Percent & $\begin{array}{c}\text { Cumulative } \\
\text { Percent }\end{array}$ \\
\hline Valid & 0 & 5 & 5.0 & 5.0 & 5.0 \\
\hline & 1 & 4 & 4.0 & 4.0 & 9.0 \\
\hline & 2 & 12 & 12.0 & 12.0 & 21.0 \\
\hline & 3 & 14 & 14.0 & 14.0 & 35.0 \\
\hline & 4 & 20 & 20.0 & 20.0 & 55.0 \\
\hline & 5 & 25 & 25.0 & 25.0 & 80.0 \\
\hline & 6 & 12 & 12.0 & 12.0 & 92.0 \\
\hline Total & 7 & 8 & 8.0 & 8.0 & 100.0 \\
\hline
\end{tabular}

Finally the principle of dialogic loop was examined with the use of three variables. From the table 1.5 it is obvious that the majority of the web sites do not contain any of the variables (34\%) followed by those containing two $(25 \%)$. It is remarkable that the minority of the sites (18\%) contain all the three variables. From the data gathered it is derived that educational institutions do not give too much attention in order to crate dialogic loops.

Table 1.6

\begin{tabular}{|l|c|c|c|c|c|}
\hline & & Frequency & Percent & Valid Percent & $\begin{array}{c}\text { Cumulative } \\
\text { Percent }\end{array}$ \\
\hline Valid & & & 34.0 & 34.0 & 34.0 \\
\hline & 0 & 34 & 23.0 & 23.0 & 57.0 \\
\hline & 1 & 23 & 25.0 & 25.0 & 82.0 \\
\hline Total & 2 & 18 & 18.0 & 18.0 & 100.0 \\
\hline
\end{tabular}

In order to give a complete answer to RQ1 we summarize to the table below all the variables calculating also the mean the standard deviation and cronebach alpha for each principle 


\begin{tabular}{|c|c|c|c|}
\hline & MEAN & Std & Alpha \\
\hline Ease of interface & 60 & 19.17246 & 0.5271 \\
\hline Existence of site map & 50 & & \\
\hline Links connecting with other departments of the faculty & 89 & & \\
\hline Existence of search engine & 51 & & \\
\hline Low graphical reliance & 51 & & \\
\hline Usefulness of information for the external public & 71.66667 & 20.432 & 0.7095 \\
\hline Announcements & 93 & & \\
\hline Location and access & 73 & & \\
\hline Telephone catalog & 55 & & \\
\hline Information about graduate studies & 99 & & \\
\hline Information about postgraduate studies & 60 & & \\
\hline Proclamations & 50 & & \\
\hline Usefulness of information for the internal public & 72.8 & 19.26655 & 0.5626 \\
\hline Mission statement - philosophy & 90 & & \\
\hline Information about enrollment procedure & 62 & & \\
\hline Student's care & 48 & & \\
\hline Electronic access to the library & 70 & & \\
\hline Timetable of the semester & 94 & & \\
\hline Conservation of visitors & 63.33333 & 24.82606 & 0.2535 \\
\hline Important information located on the main page & 92 & & \\
\hline Time for the website to load (less than $4 \mathrm{sec}$ ) & 49 & & \\
\hline Posting of last updated date & 49 & & \\
\hline Generation of return visits & 44.77778 & 35.98534 & 0.7106 \\
\hline Statement inviting user to return & 11 & & \\
\hline Existence of Forums & 19 & & \\
\hline $\begin{array}{l}\text { Existence of Frequently Asked Questions (FAQs) or Questions and } \\
\text { Answers (Q\&As) }\end{array}$ & 13 & & \\
\hline Invitation to bookmark the address of the web site & 0 & & \\
\hline Links connecting with other web sites & 90 & & \\
\hline Calendar of Academic Events & 38 & & \\
\hline Downloadable files & 65 & & \\
\hline E-mail of a contact person & 88 & & \\
\hline Regular updates of new information (at least every thirty days) & 79 & & \\
\hline Dialogic loop & 42.33333 & 8.082904 & 0.6278 \\
\hline Opportunity for on line applications & 41 & & \\
\hline E-mail of the network operation center & 35 & & \\
\hline E-mail of the secretary's office & 51 & & \\
\hline
\end{tabular}

Although the principle of dialogic loop can be used in order to answer RQ3 a further examination of the efforts that educational institutions make in order to establish a dialogic relationship with the visitors of their web sites was conducted with the use of electronic mail. An electronic mail was sent to the e-mail address that we found in each web site and tow week's time was given in order to receive an answer from the educational institution. An actual dialogic response creates a more accurate measure of an institution's dialogic potential than simply whether visitors can "respond" or "express an opinion" (Taylor et al. 2001).

Each educational institution was coded as responsive (1) if there was a respond to the message above or nonresponsive (0) if after two weeks time there was no response. From the 100 web sites only forty (40\%) educational institutions reply while the other sixty failed to answer. 
Taken into consideration the variable of responsiveness or non-responsiveness the web sites were classified again for each principle. As the table 1.6 indicates for each of the six principles responsive institutions scored higher than non -responsive.

Table 1.7

\begin{tabular}{|l|c|c|}
\hline & Responsiveness & Non-Responsiveness \\
\hline & Mean (\%) & Mean (\%) \\
\hline Ease of interface & 71.25 & 53 \\
\hline Usefulness of information from the external public & 81.3 & 65.3 \\
\hline Usefulness of information from the internal public & 82 & 66.6 \\
\hline Conservation of visitors & 65 & 62.3 \\
\hline Generation of return visits & 53 & 39.1 \\
\hline Dialogic loop & 53 & 35 \\
\hline
\end{tabular}

Discriminal analysis was used in an effort to classify the observations into known populations with known distribution for each population. The purpose of this disciminant function is to separate each observation to the two known groups. A discriminant function is successful when it distributes correct as many observations as possible. In our case the results of discriminal analysis are shown in the table below:

\begin{tabular}{|c|c|c|c|c|c|}
\hline \multicolumn{6}{|c|}{ Classification Results } \\
\hline & & & $\begin{array}{c}\text { Predicted Group } \\
\text { Membership }\end{array}$ & & Total \\
\hline & & $\begin{array}{c}\text { Responsivness or } \\
\text { non Responsiveness }\end{array}$ & 0 & 1 & \\
\hline \multirow[t]{4}{*}{ Original } & Count & 0 & 38 & 22 & 60 \\
\hline & & 1 & 11 & 29 & 40 \\
\hline & $\%$ & 0 & 63.3 & 36.7 & 100.0 \\
\hline & & 1 & 27.5 & 72.5 & 100.0 \\
\hline \multirow[t]{4}{*}{\begin{tabular}{|l|} 
Cross-validated \\
\end{tabular}} & Count & 0 & 38 & 22 & 60 \\
\hline & & 1 & 13 & 27 & 40 \\
\hline & $\%$ & 0 & 63.3 & 36.7 & 100.0 \\
\hline & & 1 & 32.5 & 67.5 & 100.0 \\
\hline
\end{tabular}

(A) Cross validation is done only for those cases in the analysis. In cross validation, each case is classified by the functions derived from all cases other than that case. (B) $67.0 \%$ of original grouped cases correctly classified. (C) $65.0 \%$ of cross-validated grouped cases correctly classified.

From the table above it is derived that the discriminant function correctly classifies 67 out of the 100 web sites. Of the sixty non-responsive educational institutions thirty-eight $(63.3 \%)$ were classified correctly while twentytwo (36.7\%) wrong. On the other hand from the forty responsive educational institutions twenty-nine (72.5\%) were classified correctly while eleven (27.5\%) wrong. As a result responsive web sites are easier to predict than nonresponsive.

Wilks' Lambda

\begin{tabular}{|c|c|c|c|c|}
\hline Test of Function(s) & Wilks' Lambda & Chi-square & df & Sig. \\
\hline 1 & .829 & 17.789 & 6 & .007 \\
\hline
\end{tabular}

Wilks'Lambda provides useful information for the differences between the two groups, showing the percentage of the variance that could not be explained by the model. Since the index is close to one then the percentage is negligible. 
Table 1.8 indicates the standardized canonical discriminant function coefficients. These coefficients explain (a) the weight of each dialogic communication principle on responsiveness and (b) that higher values on a principle contribute to a web site being classified as responsive (positive coefficient) or non responsive (negative coefficient). In other words the higher a negative value on a principle the lesser this principle describes a responsive web site. The opposite occur for a positive value.

Table 1.8 Standardized Canonical Discriminant Function Coefficients

\begin{tabular}{|l|c|}
\hline & Function \\
\hline & 1 \\
\hline Ease of interface & .318 \\
\hline Usefulness of information for external public & .142 \\
\hline Usefulness of information for internal public & .284 \\
\hline Conservation of visitors & -.584 \\
\hline Generation of return visits & .683 \\
\hline Dialogic loop & -.036 \\
\hline
\end{tabular}

\section{CONCLUSIONS}

The data collected were used to explore how Greek educational institutions use the Internet in terms of public relations and more specific in terms of dialogue. Educational institutions use applications of the Internet such as web sites or e-mails and it is quite unusual for them not to have a web site. For the purposes of this study we followed the five dialogic principles founded by Kent and Taylor (1998).

The web sites of Greek educational institutions in their majority meet the technical and design aspects required for dialogic relationship building. There are some cases, for example when it comes to the usefulness of information for the publics, where the web sites concentrate high percentages - more than $70 \%$ either for internal or external public.

The informative dimension of the web sites however is not enough for two-way communication. There are principles such as the generation of return visits and the dialogic loop with low percentages - below 50\% - showing that Greek educational institutions are not yet incorporate dialogic communication into the Internet. Perhaps the public nature of the educational institutions and their difference from corporations are reducing the pressure for return visits and the creation of relations. In order to improve the interactivity between the educational institutions and their publics changes should be made towards the direction of generation of visits and the creation of dialogue.

The classification of the educational institutions to responsive and non-responsive helped even more to examine the web sites in terms of dialogue. According to the results of the research web sites that answer the e-mail that was sent to their electronic address scored better in every dialogic category. For the dialogic loop this was expected, since the answering of a message is a form of dialog, but a diffusion of improvement of the data was observed in every category proofing the dominant role of two-way communication.

Discriminant analysis showed that there could be a correct classification of the web sites based on their dialogic characteristics. Two out of three web sites $(67 \%)$ can be classified correctly by their dialogic characteristics. If the web site was previous identified as responsive the possibility of a correct classification is even bigger (72.5\%), while if it was identified as non - responsive the possibility is smaller (63.3\%). It is obvious that the identification of a web site as responsive or non-responsive is a significant element that should be taken into consideration when the examination of dialogic principles is held.

\section{FURTHER RESEARCH}

Future studies should examine the differences between Greek educational institutions and foreign educational institutions. The reasons that impose such a study are: (1) the lowering of educational barriers especially in European 
Union, (2) the mobility of the students, (3) the identification of cultural differences, (4) and the nature of the Internet, which allows worldwide access. Furthermore this will lead to a comparison of the web sites between private and public educational institutions.

\section{REFERENCES}

1. Chang L., Arnett K., Capella L., \& Beatty R., (1997), Web sites of the Fortune 500 companies: Facing customers through home pages, Information \& Management, vol. 31, pp. 335-345.

2. Daugherty M. \& Funke B., (1998), University Faculty and student perceptions of Web-based instruction, Journal of Distance Education, vol. 13

3. $\quad$ December J. \& Randall N., (1996), The World Wide Web unleashed $19963^{\text {rd }}$ ed, Indianapolis Sams.net Publishing

4. Esrock S. \& Leichty G., (1998), Social Responsibilities and Corporate Web pages: Self presentation or agenda-setting?, Public Relation Review, vol.24, pp. 305-319.

5. Esrock S. \& Leichty G., (1999), Corporate World Wide Web pages: Serving the news media and other publics, Journalism and Mass Communication Quarterly, vol. 76, pp. 456-467.

6. Greek Universities Network - Gunet web site www.gunet.gr

7. Heath R., (1998), New communication technologies: an issues management point of view, Public Relation Review, vol. 24, pp. 273-287.

8. Heeter C., (1989), Implications of new interactive technologies for conceptualizing communication, In J.L.Salvaggio \& J.Bryant (Eds), Media use in the information age: emerging patterns of adoption and consumer use. Hillsdale, NJ: Erlbaum.

9. Kannan P., Chang A., \& Whinston A., (1998), Marketing information on the I-way: Data junkyard or information gold mine? Communication of the ACM, vol. 41, pp. 35-43.

10. Kent M. \& Taylor M., (1998), Building dialogic relationships through World Wide Web, Public Relation Review, vol. 24, pp. 321-334.

11. Kent M., (2001), Teaching Mediated public relations, Public Relation Review, vol. 27, pp. 59-71.

12. Kent M., Taylor M., \& White W., (2003), The relationship between Web site design and organizational responsiveness to stakeholders, Public Relation Review, vol. 29, pp. 63-77.

13. Meyer P., (2002), Precision journalism: A reporter's introduction to social science methods $4^{\text {th }}$ edition, Lanham, Maryland: Rowman \& Littlefield.

14. Naude A., Froneman J., Atwood R., (2004), The use of the Internet by ten South African non-governmental organizations - a public relation perspective, Public Relations Review, vol. 30, pp. 87-94.

15. Peterson R., Balasubramanian S. \& Bronnenberg B., (1997), Exploring the implications of the Internet for consumer marketing, Journal of the Academy of Marketing Science, Fall, pp. 329-346.

16. Rogers E. \& Allbritton M., (1995), Interactive Communication Technologies in Business Communications, Journal of Business Communication, vol. 32, pp. 177-195.

17. Roland R. \& Varik S., (1996), Rising from the ashes of advertising, Journal of Business Research, vol. 37 , pp. $173-181$.

18. Taylor M., Kent M., White W., (2001), How activist organizations are using the Internet to build relationships, Public Relation Review, vol. 27, pp. 263-284.

19. Vibert C., (2000), Web-based analysis for competitive intelligence, Quorum Books. 